\title{
Dynamic thermal simulation on retrofitting scenarios for semi-extensive sheep farms
}

\author{
Maria E. Menconi, David Grohamnn, Piero Borghi \\ Department of Agricultural, Food and Environmental Sciences, University of Perugia, Italy
}

\begin{abstract}
Sheep and goat have a high adaptability to different climatic conditions. Nevertheless, even in extensive farming, these species benefit from the presence of structures that can mitigate stress from heat, cold and humidity changes. These shelters are used at night or for limited periods during the year. These are characterised by a low engineering and make extensive use of recycled material. Interesting innovation in rural areas could be represented by the re-development of these buildings in order to improve their internal microclimate. This work develops a thermal dynamic simulation model aimed at identifying the best solution to retrofit the envelope of existing livestock buildings. In this paper, three different solutions have been tested: insulation of vertical surfaces, insulation of roof and window type. Eight different materials have been considered for roof and vertical surfaces and four for the different kind of window glazing, analysing the building microclimate responses. As a reference building to compare the different solutions adopted has been chosen an extensive sheep farm located in the Italian Apennines. The results suggest that the best solution is to insulate the roof. The other elements offer negligible results in term of improving the internal microclimate conditions. For coating the roof it can also be considered a good response of all the analysed insulating materials, in order to increase the period of maintaining the temperature of comfort and not exceeding its critical values within the building.
\end{abstract}

\footnotetext{
Correspondence: Maria Elena Menconi, DSA3 Department of Agricultural, Food and Environmental Sciences, University of Perugia, via Borgo XX Giugno 74, 06100 Perugia, Italy.

Tel.: +39.075.5856024 - Fax: +39.075 .5856086 .

E-mail: mariaelena.menconi@unipg.it
}

Key words: dynamic energy simulation, microclimate responses, sheep farming, roof insulation, vertical surface insulation.

Contributions: the authors contributed equally.

Conflict of interests: the authors declare no potential conflict of interests.

Received for publication: 19 May 2014.

Accepted for publication: 17 July 2014.

(C) Copyright M.E. Menconi et al., 2014

Licensee PAGEPress, Italy

Journal of Agricultural Engineering 2014; XLV:235

doi:10.4081/jae.2014.235

This article is distributed under the terms of the Creative Commons Attribution Noncommercial License (by-nc 3.0) which permits any noncommercial use, distribution, and reproduction in any medium, provided the original author(s) and source are credited.

\section{Introduction}

Sheep farming can be considered a niche market within the vast framework of agriculture activities, representing just 7\% of the European livestock market (European Commission, 2012a). However, in several Mediterranean countries, e.g. Greece, Italy and southern France, this percentage increases greatly, until reaching remarkable values. In Greece sheep farming represents almost the $43 \%$ of the total livestock activities (European Commission, 2012a). In many rural areas within the European Community member states, extensive sheep farming represents an important resource. In particular for those located in the Mediterranean area on hills or mountains with high landscape value, extensive sheep farming is not only the longest practiced animal farming activity, but also the most interesting considering its adaptability to the territorial morphology and the restrictions that have been established over the years in terms of sustainable rural development practices. Besides, extensive sheep farming plays the pivotal role of territorial protection and low-level governance in marginal rural territories otherwise destined to depopulation and abandonment and can be considered one of the livestock activities more sustainable from an environmental point of view (Thompson, 2009).

Generally the buildings for semi-extensive livestock farming are quite heterogeneous in terms of material and geometries, low cost, without active control of the environmental conditions and with a low level of technology and structures engineering. In fact, the low profit margins of these activities, the low concentration of animals and the short time that they remain confined inside the barn, discourages the inclusion of heating, ventilating, and air conditioning system. Nevertheless, thermal efficient control of microclimate conditions in extensive livestock buildings is very important for sustainable livestock production and animal welfare (Caroprese, 2008; Ecim-Djuric and Topisirovic, 2010; Van Laer, 2014).

Contrary to what is true for the majority of industrial buildings, the livestock buildings are not only the place of production, but represent an important production factor for the influence they can have on the productivity of the animals and on the operators job. It is known that the whole productive potential of the animals can be reached only with the optimisation of all the production factors, not least those microclimatic, even for small ruminants, although there are several species adapted to harsh climatic conditions (Chiappini, 1994; Berge, 1997; Goddard et al., 2006; Manninen et al., 2008; Salama et al., 2014).

When dynamic energy simulations are applied to livestock buildings, they are mostly dedicated to cattle and swine intensive farming (Jäkel, 2003; Kraatz and Berg, 2007; Fabrizio and Airoldi, 2012).

Energy efficiency of buildings is a central thematic on EU-level (European Commission, 2002, 2010, 2012b) and on national level (for Italy: Italian Regulation, 2013; Ministry of Economic Development, 2012).

Accordingly, many researches have been developed for the energy performance analysis of buildings, focusing their attention mainly to residential and offices buildings (Dascalaki and Santamouris, 2002; 
Neumann et al., 2005; Escorcia et al., 2012) and to innovative design of new buildings (Ihm and Krarti, 2012; Znouda et al., 2007). In this regard many softwares and many forms of certification have been developed; for example, respectively, it is possible to cite EnergyPlus the Energy Simulation Software (U.S. Department of Energy, Washington, DC, USA, http:/apps1.eere.energy.gov/buildings/energyplus/?utm_source=EnergyPlus\&utm_medium=redirect\&utm_campaign=EnergyPlus\%2Bredirect\%2B1), RETScreen ${ }^{\circledR}$ International (Government of Canada, Natural Resources Canada, http://www. retscreen.net/ang/home.php) and DOE (U.S. Department of Energy, Washington, DC, USA, http://www.doe2.com), or LEED (Kubba, 2009), BREEAM $^{\circledR}$ (BRE Global, Watford, UK, http://www.breeam.org/ podpage.jsp?id=665), Green Globes (ECD Energy and Environment, Canada, http//www.greenglobes.com/home.asp), Passivhaus (Passive House Institute, Darmstadt, Germany, http://passiv.de/en/index.php), MINERGIE ${ }^{\circledR}$ (MINERGIE Building Agency, Bern, Switzerland, http://www.minergie.ch/home_en.html) and Casaclima (ClimateHouse Agency, Bolzano, Italy, http://www.klimahaus.it/en/).

When this consideration are applied to existing buildings, we need to take into account the difficulties of being unable to act on key elements such as the orientation of the structures, the exposure and the window to wall ratio. In these cases, the most viable and economic solution is to intervene on the envelope of these structures, modifying their thermal inertia, making use of insulating materials (Dascalaki and Santamouris, 2002; Al-Ragom, 2003; Verbeeck and Hens, 2005). Walls and roofs of the building envelope play an important role in the heat transfer between the exterior and the interior spaces of the building. From a thermal point of view, a good wall/roof contributes to the thermal comfort conditions inside the building without using heating or cooling air-conditioning systems.

The research is part of a larger work that aims to revitalise sheep starvation-mismothering exposure (SME) farms in marginal areas, offering them services and suggestions to achieve appropriate living conditions for operators and animals.

With this in mind it was decided to develop a thermal dynamic simulation model aimed at identifying the best solution to retrofit the envelope of existing livestock buildings.

\section{Materials and methods}

The dynamic thermal model simulations were carried out hourly for one year (8760 values).

System dynamics modelling involves the application of certain mathematical techniques with a particular perspective on the modelling process and interpretation of modelling outputs (Tedeschi, 2011). The methodology couples a software dedicated to simulate the trend of dynamic thermal models with a software dedicated to the 3D modelling of the building: EnergyPlus, elaborated by the U.S. Department of Energy and Google SketchUp. In order to communicate, these softwares use a plugin for SketchUp, named OpenStudio.

These software have been selected as they are free downloadable, furthermore, EnergyPlus is one of the most complete and used software for dynamic simulation of the energy performance available (Chioua et al., 2011; Mazo et al., 2012; Marini, 2013) and Google SketchUp is the easiest and entirely free 3D drawing tool available (Kurtulus and Uygan, 2010; Brixius, 2011).

The flowchart of the methodology is shown in Figure 1.

The building model (called case study) includes the geometric characteristics (3D model), a description of the materials (properties and thickness) that compose the opaque and transparent surfaces, the definition of its exact geographical location, its orientation, the modelling of infiltration and the description of the gain/consumption factors

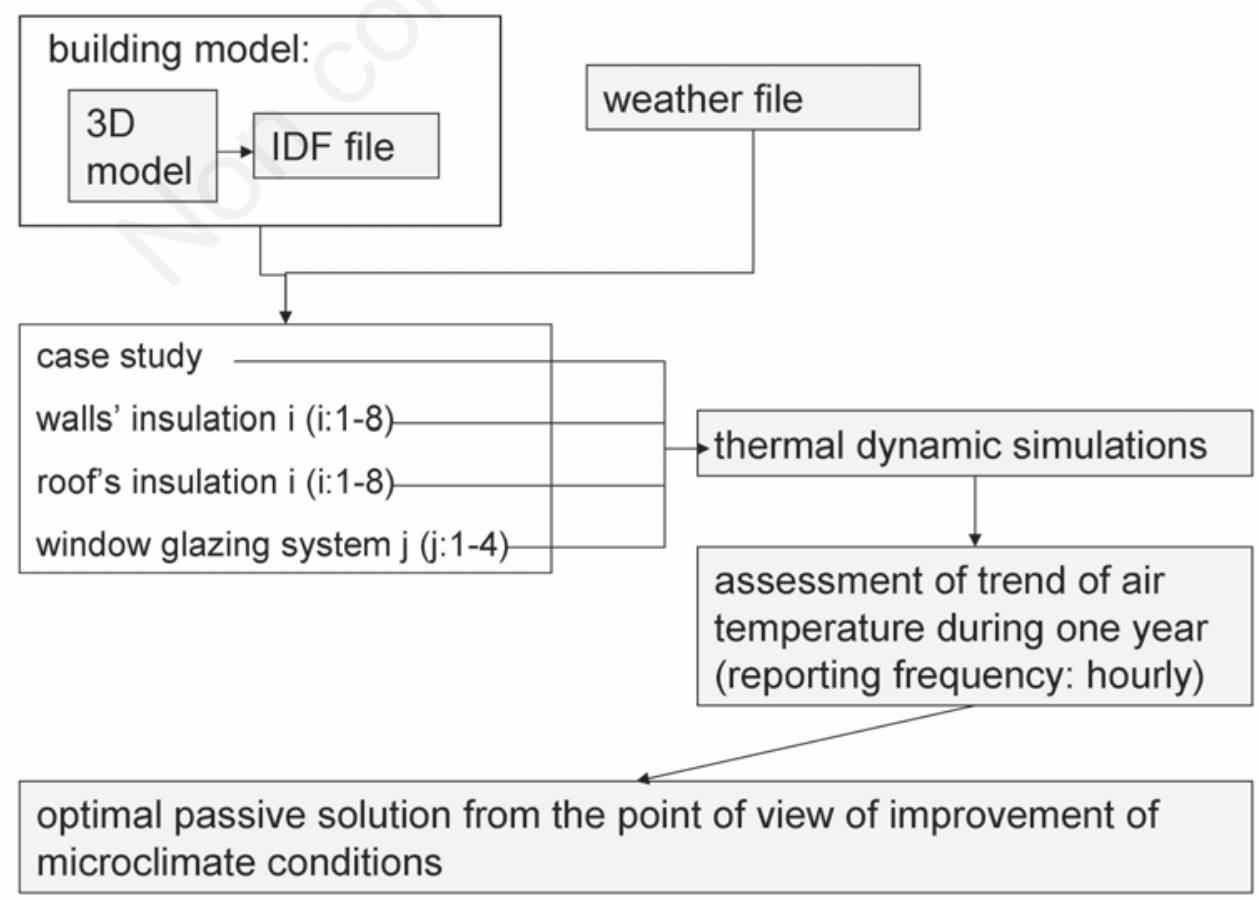

Figure 1. Methodology flowchart. 
(timetable of presence and activity level for people and animals, timetable of functioning and lighting level for lights, timetable of functioning and design level for electric equipment).

For this study the building model used is an extensive sheep farm is located in the Italian Apennines (Figure 2). The sheepfold was built in 1993 (stable) and later expanded in 1999 with the creation of a warehouse and a milking parlor. The building is organised in three structures: the stable, the milking parlor and the warehouse. The building is exposed to the Northeast along the longitudinal axis of the fold; the openings are represented by aluminium doors and by single glass aluminium frame windows. Construction materials consist of steel for structures such as pillars and trusses, concrete blocks for the infill and concrete slabs for cover. The sheepfold, at full capacity, can accommodate about 200 sheep. The births take place twice a year, in winter from February to April and during the summer from July to September. For each of these periods there are approximately 95 births. The sheep are housed the whole day in the stable only in winter; in summer only those with lamb. For the rest of the year all the animals are located in the barn only at night. For the periods from April to June and from September to December, the animals are milked twice a day.

The 3D model was designed following the characteristic of the sheepfold summarised in Table 1. With regard to the internal gains the characteristics are included in the IDF file, i.e. in Table 2 are shown the values for the stable. The windows are always kept open during the summer months and remain closed for the rest of the year; with regard to the doors in the model they were assumed always open in the daytime in summer and when the operators are present for the remaining months, as well.

The outdoor climate conditions have a significant influence on the behaviour of a building, so to capture these effects is used a weather file. From the U.S. Department of Energy website there are numerous free downloadable weather files. For using in EnergyPlus, a weather file must have the extension .epw and a typical meteorological year (TMY) data format is used. TMY is the most common data for describing the local solar climate and it is frequently used in building simulation (Guggenberger et al., 2013; Nguyen and Reiter, 2014). This format is good for understanding/predicting how a building will react during typical conditions and for comparative energy efficiency study (Yang et $a l ., 2008)$. Hourly data typically stored in the .epw file for EnergyPlus are 23 solar variables, 6 sky cover variables (e.g. clouds), 12 temperature, humidity, pressure variables, 6 wind variables, 6 visibility variables and 10 precipitation variables. Once the location is identified (name, latitude, longitude, time zone, elevation) the closest available weather file is selected. The building model is located in central Italy and the nearest weather file downloadable from the U.S. Department of Energy website is ITA_perugia.161810_IGDG.

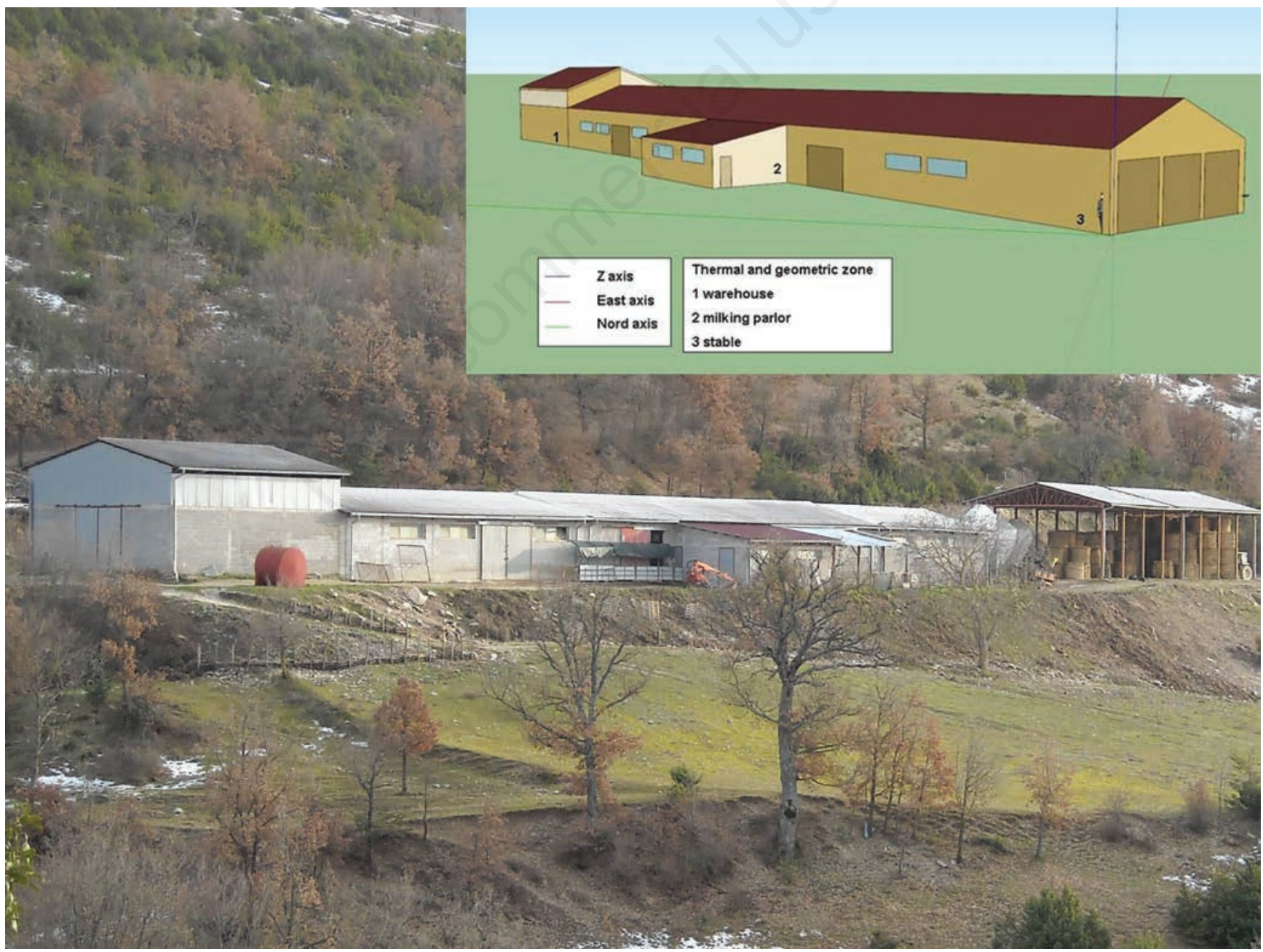

Figure 2. Existent sheepfold used how building SketchUp model (Umbria Region). 
The choice to avoid the elaboration of a dedicated weather file is justified when multiple design alternatives are compared in order to identify the best one. In those cases in which an evaluation of the actual energy consumption of the building is needed, the input weather file should be from the exact location of the structure.

As indicators of the micro-climatic conditions, the trends of air temperature inside the stable were simulated during one year (reporting frequency: hourly), for the different design alternatives. A subsequent paper will cover similar assessments for the zone air relative humidity trends.

Once performed the simulation of the air temperature trend inside the stable, the model is adjusted incrementally to achieve more efficient performance scenarios, through the evaluation of the addition of different insulation materials to the original envelope's roof or to the original vertical surfaces or changing different materials for the transparent surfaces. It was chosen to elaborate 20 different design alternatives, using 8 insulating materials for the roof and vertical surfaces and 4 different types of windows; the characteristics of different passive solutions are summarised in Table 3.

The optimal passive solution was evaluated by calculating the number of hours/year in which are maintained the non-critical and comfort values of temperature; these values are dependent on the animal species farmed, the type of farming and the type of livestock manage- ment (intensive, extensive, mixed forms).

The obtained results were compared with the simulation relative to the case study model in terms of the number of days of comfort earned (gain of comfort $\mathrm{G}_{\mathrm{com}}$ ) and avoidance in exceeding the critical values (gain of non critical values $\mathrm{G}_{\mathrm{cr}}$ ) according to Eq. (1) and Eq. (2).

$$
\begin{aligned}
& \mathrm{G}_{\mathrm{s} \_ \text {com }}=\left(\begin{array}{ll}
\mathrm{dCS}_{\mathrm{com}} & \mathrm{dS}_{\mathrm{s} \_ \text {com }}
\end{array}\right) / 24 \\
& \mathrm{G}_{\mathrm{i} \_\mathrm{cr}}=\left(\begin{array}{ll}
\mathrm{dCS}_{\mathrm{cr}} & \mathrm{dS}_{\mathrm{s} \_\mathrm{cr}}
\end{array}\right) / 24
\end{aligned}
$$

where $s$ is the counter for different passive solution applied, $\mathrm{dCS}_{\mathrm{com}}$ and $\mathrm{dCS}_{\mathrm{cr}}$ are respectively the hours/year in which the case study model exceeds the comfort and critical values; similarly for $\mathrm{d} \mathrm{S}_{\mathrm{s}}$ with regard to the ${ }_{\text {s-th }}$ passive solution evaluated. The value 24 represents the number of hours contained in a day. For values that leak out from non critical and comfort temperature ranges were assessed the hours when the animals were at too low temperatures and periods in which the animals were exposed at too high temperatures, in order to offer information regarding the effectiveness of the different solutions in different months of the year, as well. We referred to Chiumenti studies (1987) to fix the optimal and critical temperature ranges for sheep and lambs and these values were reported in Table 2 .

The material that has the highest number of days in which the build-

Table 1. Envelope characteristics and location of case study - model building.

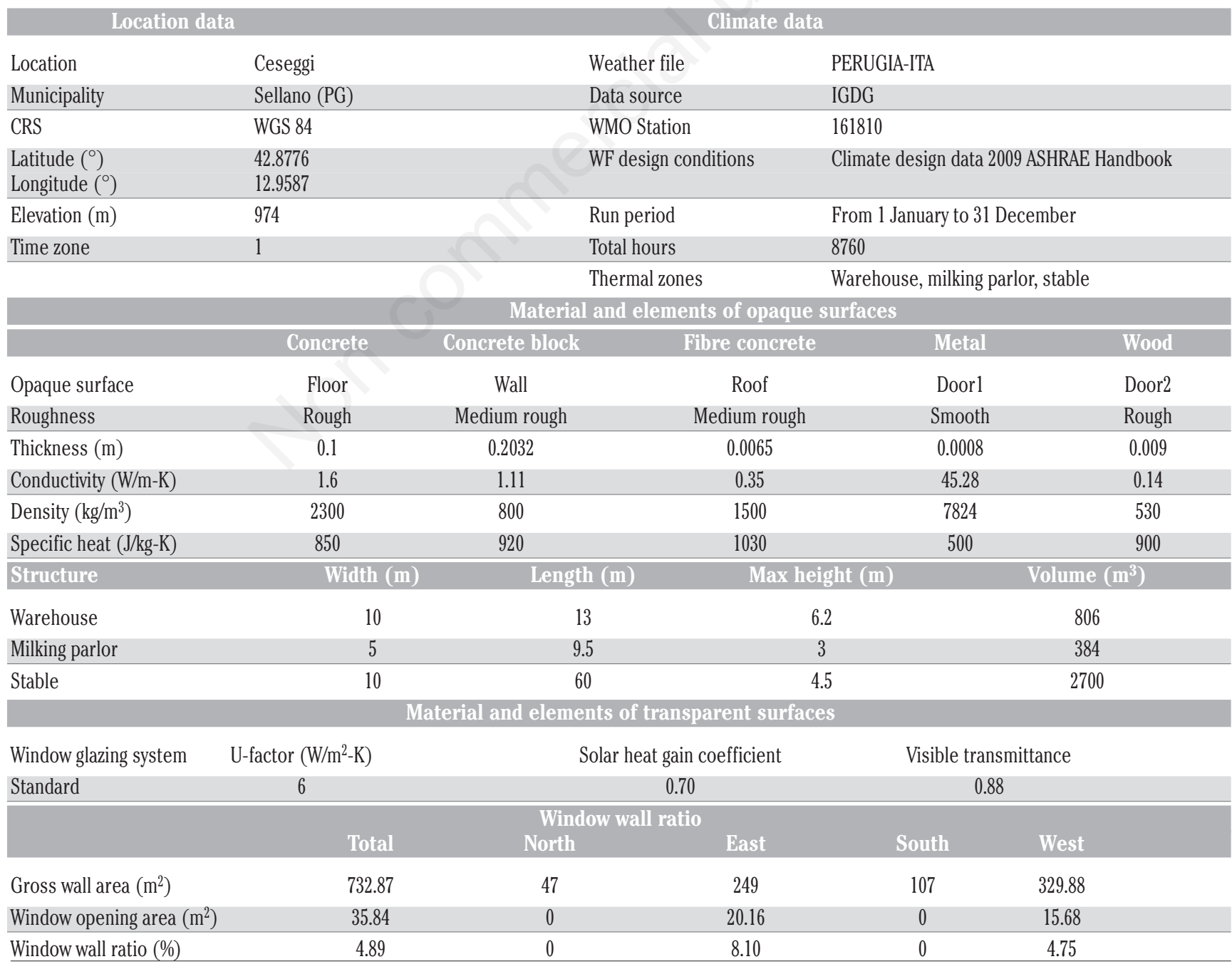


ing internal temperature pattern is improved, is considered the optimal passive solution from the animal welfare point of view.

\section{Results}

Using the EP-launch tool 21 simulations were run (one for model building and the remaining 20 for the design alternatives) on an hourly basis. All simulations used the same weather file to simulate the variation of the external climatic conditions and were conducted for a time period equal to one year. In the IDF file it was set, as output reporting, the hourly temperature trend inside the stable.

\section{Building model: thermal simulations}

Figure 3 shows the trend of the temperature inside the stable during the year of simulation. The green and red coloured areas respectively represent the ranges in which the temperature can be considered within the values of comfort and outside the critical values. The two steps present in the coloured areas in Figure 3 represent the two periods in which, in stable, there are simultaneously sheep and lambs. From Figure 3 it can be observed how the trend of air temperature inside the stable is characterised by exceedances of the critical and comfort temperatures, mainly during summer months. Forty-five percent of the year the stable lies above the maximum temperature of comfort and $38 \%$ of this (17\% of the year) is above the maximum critical temperature. With regard to the minimum values, we found that the stable for
$21 \%$ of the year is below the minimum comfort temperature and $19 \%$ of this ( $4 \%$ of the year) is below the lowest critical temperature.

\section{Alternative solutions: thermal simulations}

The Table 4 shows the different hours/year (expressed in number of hours and percentage) when air temperature of the stable has critical values or distress values, to the varying of the design solutions.

In the calculation of the gained hours were considered only the hours when there are animals in the stable.

From Table 4 it can be observed how the gain in hours within comfort and critical temperatures ranges has interesting improvements only for passive solution involving the insulation of the roof.

In fact, for the roof, the gain during one year of simulation surmounts one month (30 days), for all the alternative insulation materials tested; instead, for the other solutions (walls and windows) the gain does not surmount 4 days.

The results suggest that the best solution is to insulate the roof, as expected (Jayasinghe et al., 2003). The other hypothesis offers negligible results in term of improving the internal microclimate conditions. Table 4 also shows how the different solutions are all improvements over the case study, in terms of maintaining the temperature above the minimum, while resulting in some cases worse due to the reduced dispersion of excess heat during the summer months. Figure 4 shows the response of all design solutions distinguishing their contribution in terms of hours/year, over/under the comfort and non critical temperatures: the more the solution is close to the centre of the diagram, the

Table 2. Internal gains characteristics of case study - model building for the thermal zone: stable [these optimal and critical temperature ranges for sheep and lambs are reported in Chiumenti studies (1987)].

\begin{tabular}{|c|c|c|c|c|c|}
\hline $\begin{array}{l}\text { Presence time ( } 0 \\
\text { Time band }\end{array}$ & armer) & $\begin{array}{l}\text { chedules of interna } \\
\text { Periods }\end{array}$ & $\begin{array}{l}\text { ins for the stable } \\
\text { Presence time (a } \\
\text { Time band }\end{array}$ & Sheep & Lambs \\
\hline From $01 / 01$ to $31 / 03$ & 8 & From $01 / 01$ to $31 / 31$ & 0:00-24:00 & 200 & 0 \\
\hline From $01 / 04$ to $30 / 04$ & 4 & From $01 / 04$ to $30 / 04$ & $\begin{array}{l}\text { 0:00-06:00 } \\
\text { 6:00-20:00 }\end{array}$ & $\begin{array}{c}200 \\
0\end{array}$ & $\begin{array}{l}0 \\
0\end{array}$ \\
\hline From $01 / 05$ to $31 / 05$ & 10 & From $01 / 05$ to $31 / 05$ & $\begin{array}{c}0: 00-06: 00 \\
6: 00-20: 00 \\
20: 00-24: 00\end{array}$ & $\begin{array}{c}200 \\
95 \\
200\end{array}$ & $\begin{array}{l}95 \\
95 \\
95\end{array}$ \\
\hline From $01 / 06$ to $30 / 09$ & 4 & From $01 / 06$ to $30 / 09$ & $\begin{array}{c}0: 00-06: 00 \\
6: 00-20: 00 \\
20: 00-24: 00\end{array}$ & $\begin{array}{c}200 \\
0 \\
200\end{array}$ & $\begin{array}{l}0 \\
0 \\
0\end{array}$ \\
\hline From $01 / 10$ to $30 / 10$ & 10 & From $01 / 10$ to $30 / 10$ & $\begin{array}{c}0: 00-06: 00 \\
6: 00-20: 00 \\
20: 00-24: 00\end{array}$ & $\begin{array}{c}200 \\
95 \\
200\end{array}$ & $\begin{array}{l}95 \\
95 \\
95\end{array}$ \\
\hline From $01 / 11$ to $31 / 12$ & 4 & From $01 / 11$ to $31 / 12$ & $\begin{array}{c}0: 00-08: 00 \\
8: 00-18: 00 \\
18: 00-24: 00\end{array}$ & $\begin{array}{c}200 \\
0 \\
200\end{array}$ & $\begin{array}{l}0 \\
0 \\
0\end{array}$ \\
\hline Occupants & $\begin{array}{c}\text { Activity level } \\
\text { (w/person) }\end{array}$ & Occupants & Optimal T range $\left({ }^{\circ} \mathrm{C}\right)$ & Critic & je $\left({ }^{\circ} \mathrm{C}\right)$ \\
\hline Farmer & 216 & Sheep & $10-17$ & & \\
\hline Sheep & 115 & Lamb 0-2 weeks & $20-22$ & & \\
\hline Lamb & 60 & Lamb 3-4 weeks & $15-18$ & & \\
\hline Internal gain & & Level (W) & Time of use & & \\
\hline Lights & & 312 & $\begin{array}{l}\text { Winter time } 9 \mathrm{~h} / \text { day } \\
\text { Standard time during pr }\end{array}$ & of the far & \\
\hline
\end{tabular}


Table 3. Design alternatives: alternative passive solutions for the building envelope.

\begin{tabular}{|c|c|c|c|c|c|c|}
\hline Window glazing system & \multicolumn{2}{|c|}{$\begin{array}{l}\text { U-factor } \\
\left(\mathrm{W} / \mathrm{m}^{2}-\mathrm{K}\right)\end{array}$} & \multicolumn{2}{|c|}{ Solar heat gain coefficient } & \multicolumn{2}{|c|}{ Visible transmittance } \\
\hline Standard & \multicolumn{2}{|c|}{6} & \multicolumn{2}{|l|}{0.70} & \multicolumn{2}{|c|}{0.88} \\
\hline Low emission & \multicolumn{2}{|c|}{1.7} & \multicolumn{2}{|l|}{0.72} & \multicolumn{2}{|c|}{0.74} \\
\hline Selective & \multicolumn{2}{|c|}{2.1} & \multicolumn{2}{|l|}{0.55} & \multicolumn{2}{|c|}{0.61} \\
\hline Aerogel & \multicolumn{2}{|c|}{0.8} & \multicolumn{2}{|l|}{0.45} & \multicolumn{2}{|c|}{0.60} \\
\hline $\begin{array}{l}\text { Insulation material } \\
\text { (wall and roof) }\end{array}$ & $\begin{array}{l}\text { Conductivity } \\
\text { (W/m-K) }\end{array}$ & $\begin{array}{l}\text { Density } \\
\left(\mathrm{kg} / \mathrm{m}^{3}\right)\end{array}$ & $\begin{array}{l}\text { Specific heat } \\
(\mathrm{J} / \mathrm{kg}-\mathrm{k})\end{array}$ & Roughness & $\begin{array}{l}\text { Thickness } \\
\text { (m) }\end{array}$ & $\begin{array}{c}\text { Surface density } \\
\left(\mathrm{kg} / \mathrm{m}^{2}\right)\end{array}$ \\
\hline $\begin{array}{l}\text { Natural origin } \\
\text { Sheep wool } \\
\text { Mineralised wood } \\
\text { Hemp fibre } \\
\text { Cork }\end{array}$ & $\begin{array}{l}0.037 \\
0.067 \\
0.039 \\
0.040\end{array}$ & $\begin{array}{c}17.9 \\
400.0 \\
40.0 \\
150.0\end{array}$ & $\begin{array}{l}1720 \\
2100 \\
2100 \\
2100\end{array}$ & $\begin{array}{l}\text { Medium rough } \\
\text { Smooth } \\
\text { Smooth } \\
\text { Smooth }\end{array}$ & $\begin{array}{l}0.05 \\
0.05 \\
0.05 \\
0.05\end{array}$ & $\begin{array}{c}0.895 \\
20 \\
2 \\
7.5\end{array}$ \\
\hline $\begin{array}{l}\text { Synthetic origin } \\
\text { Expanded polystyrene } \\
\text { Glass wool } \\
\text { Rock fibre } \\
\text { Polyurethane }\end{array}$ & $\begin{array}{l}0.036 \\
0.032 \\
0.038 \\
0.026\end{array}$ & $\begin{array}{c}35.0 \\
13.5 \\
100.0 \\
34.0\end{array}$ & $\begin{array}{c}800 \\
850 \\
840 \\
1250\end{array}$ & $\begin{array}{c}\text { Smooth } \\
\text { Medium rough } \\
\text { Medium rough } \\
\text { Smooth }\end{array}$ & $\begin{array}{l}0.05 \\
0.05 \\
0.05 \\
0.05\end{array}$ & $\begin{array}{c}1.75 \\
0.675 \\
5 \\
1.7\end{array}$ \\
\hline
\end{tabular}

Table 4. Comparison of the behaviour of different passive solutions over one year in terms of gain in days of comfort and nonexceedance of critical temperatures.

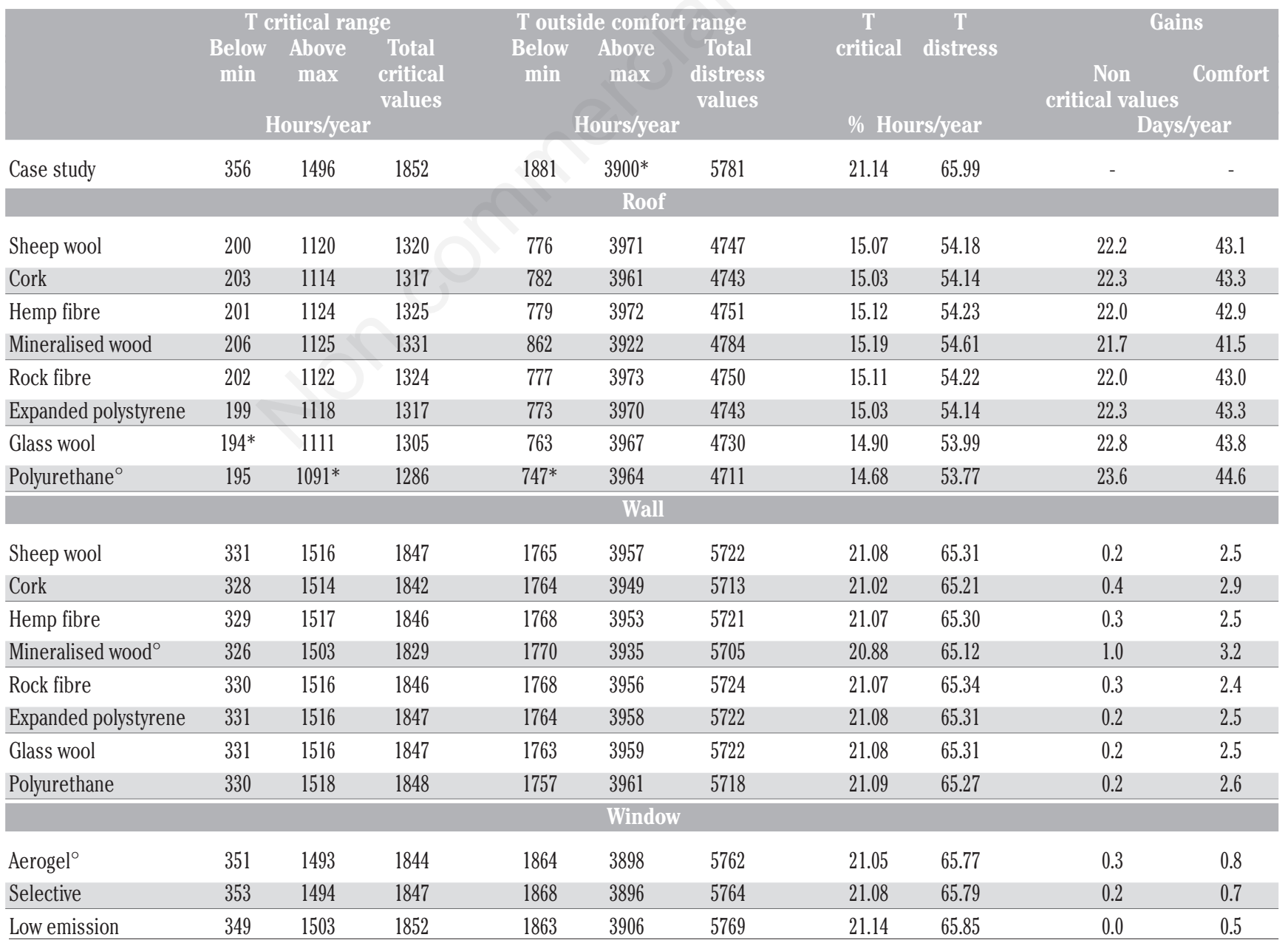

T, temperature. *Optimal values; ${ }^{\circ}$ solutions worse than the option case study. 


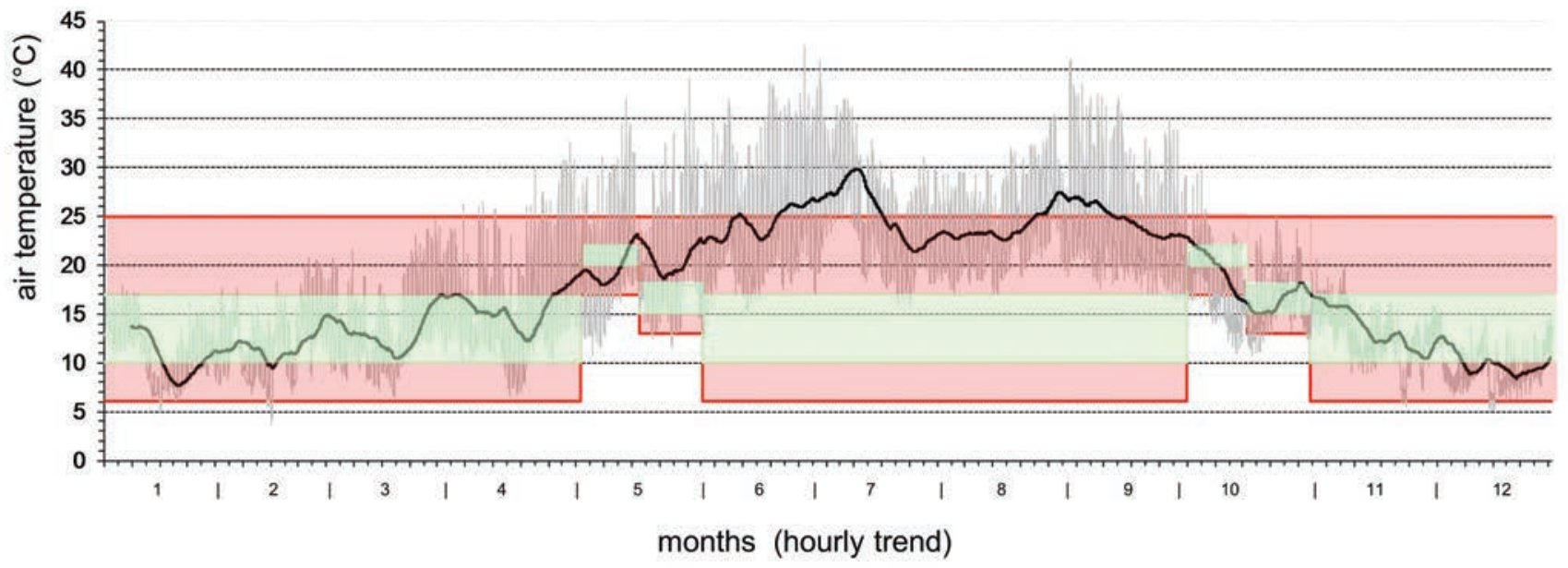

$\square$ critical T range comfort T range - CASE STUDY Air Temperature ${ }^{\circ} \mathrm{C}$ - CASE STUDY - mobile media (one week)

Figure 3. Case study building model: hourly air temperature trends inside the stable over one year (EnergyPlus hourly simulations; $x$ axis resolution: 3.5 days, $y$-axis resolution: $1^{\circ} \mathrm{C}$ ).

Legend: $\rightarrow$-roof options $\quad \rightarrow$-wall options $\quad \rightarrow$ window low emissive $\quad \rightarrow$ case study

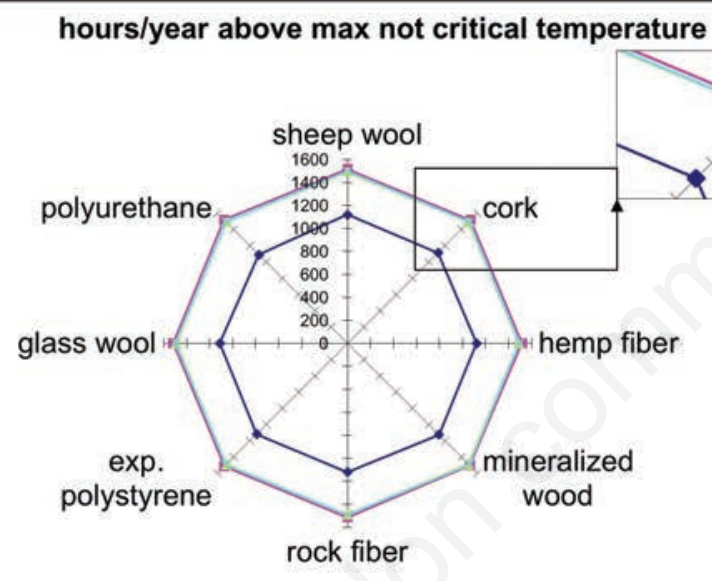

hours/year above max comfort temperature

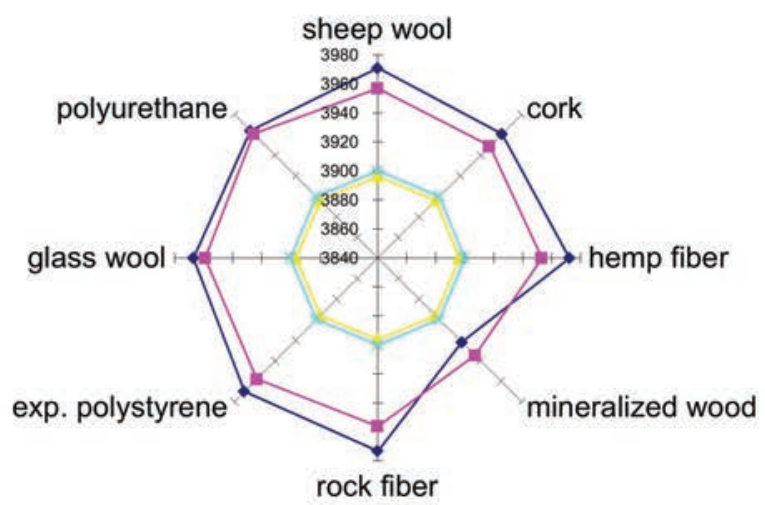

hours/year below min not critical temperature
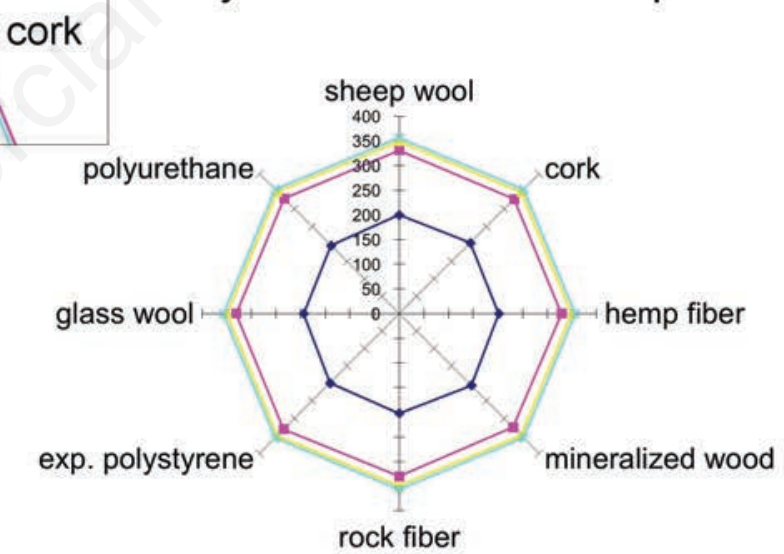

hours/year below min comfort temperature

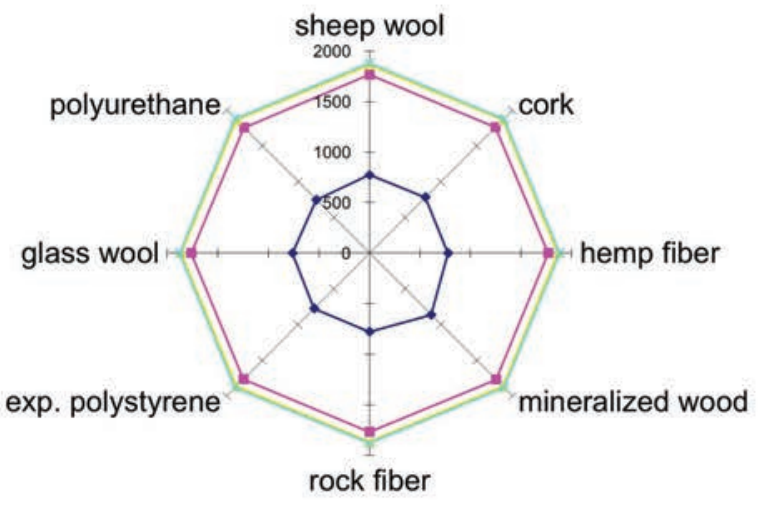

Figure 4. Comparison of the behaviour of different insulating materials regarding the four values of temperature control (EnergyPlus hourly simulations over one year). 


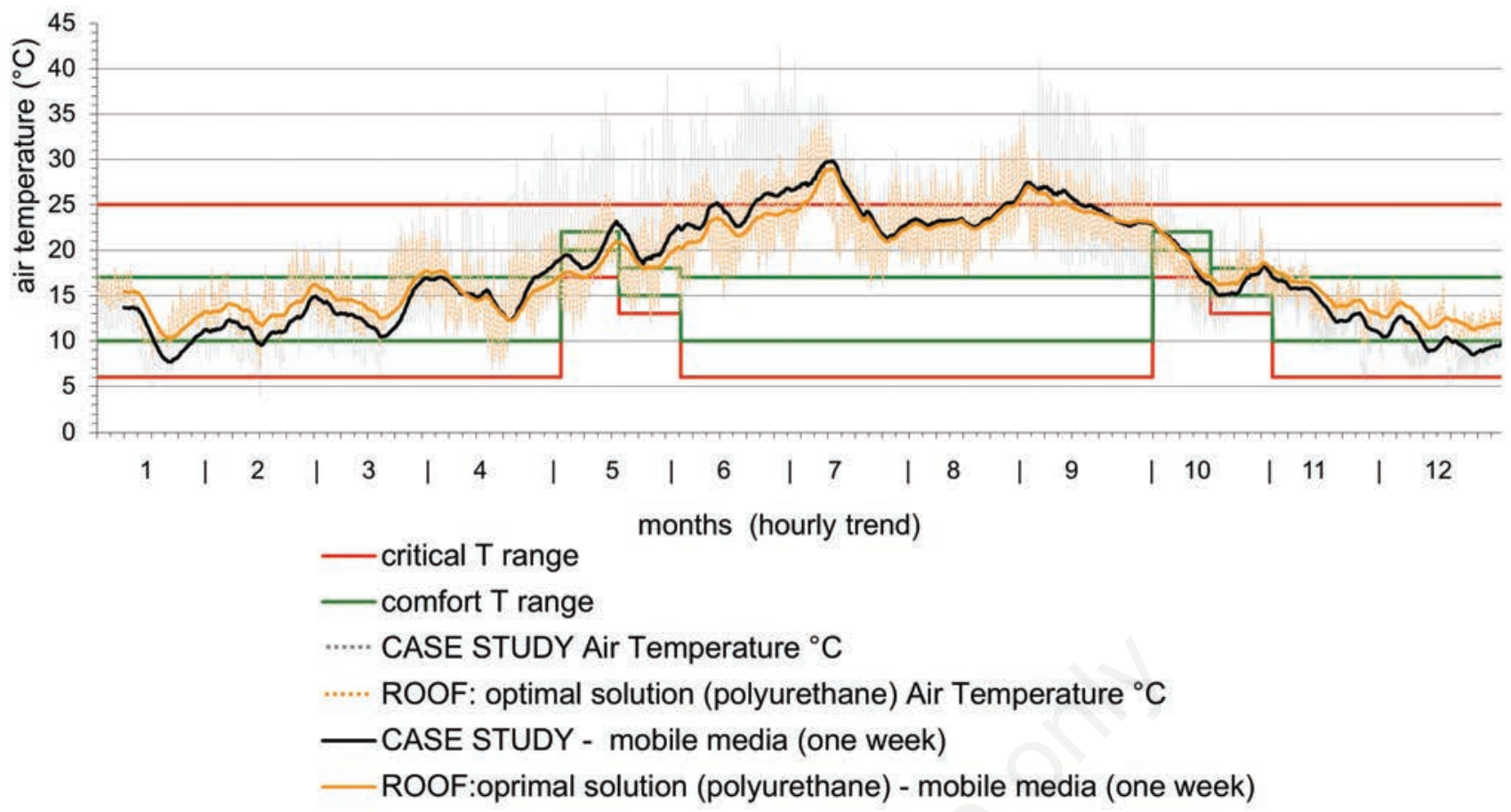

Figure 5. Comparison of the behaviour of option zero (case study) and optimal passive solution (roof's insulation - polyurethane material): hourly air temperature trends over one year (EnergyPlus hourly simulations; $\mathrm{x}$-axis resolution: 3.5 days, $\mathrm{y}$-axis resolution: $1^{\circ} \mathrm{C}$ ).

more it represents an optimal result. The worst result is given by the option zero (case study building model) in all cases, except for the maintenance of the temperature below the maximum comfort temperature, for which the addition of an insulation layer, on both roof and walls, is a pejorative choice. This happens because the insulation attenuates all peaks while maintaining the temperature within the critical range, but mean temperature shift slightly toward higher values. This could be due to the heat produced by the animals themselves that fails to be dispersed during the night. If we consider the results in terms of number of days in which the temperature is kept between the comfort and non-critical range, coating the roof can be considered a good option; from Table 4 it can be observed how the different results for the coating roof are comparable between all the analysed materials, of both natural and synthetic origin. Indeed, such intervention does earn on average 22 days/year outside the critical temperatures range and 43 days/year of comfort, with a deviation between the different design solutions, compared to the mean value, always below of 1.68 days/year.

Figure 5 shows the temperatures hourly trend with the moving average calculated over a period of $168 \mathrm{~h}$ (hours in a week), for the best solution (roof insulation with polyurethane) and for the case study.

\section{Conclusions}

By analysing the results, we can say that for sheepfold located in mild-cold areas to apply a roof insulation is an excellent solution. With regard to the farms located in low hilly areas, it should be considered positive response in the summer months are not always achieved. A possible successful intervention could involve the insertion of remov- able panels, but this solution would be very expensive. The negligible contribution relative to those solutions involving transparent surfaces, as compared to other applications elaborate for residential housing (Díaz et al., 2012), is explainable due to the low window to wall ratio that characterises the sheepfold.

An important future development for this study would be to generate a weather file dedicated to the study area to perform an experimental test suitable to assess how the building model simulation is close to real conditions for the animals in the stable.

As regards the choice of the best material to be inserted as insulation, the polyurethane is a valid alternative, but since the results are all very close other criteria should be considered (Charlot-Valdieu and Outrequin, 2011; Rua and Lopez-Mesa, 2012) to identify the optimal solution (e.g. the costs of buying and installation, PEI, etc.).

The choice regarding the best insulating material to be used should also take into consideration its availability on site, for example sheep wool has good performance and, in the case of sheepfold, could be considered a viable alternative. In this case there would be the need to relate the sheep farms that possess the raw material with companies who treat those materials for insulation.

To fully evaluate the improvement of the animal welfare, the subsequent contribution will cover similar evaluations concerning the air humidity. A further contribution to the research concerns the development of a system dynamic model to evaluate different solution for ventilation.

Type of farming and climatic zone influence the response of passive solutions applicable on retrofitting scenarios for livestock buildings, therefore this work is intended to serve as an assessment tool to support farmers and other decision-makers in identifying optimal passive features to improve animal welfare and energy performance of existing livestock buildings, and not to supply one specific solution. The devel- 
oped methodology can be replicated in different cases by varying climatic input data and the building's characteristics.

To ensure the sustainability of a farm, the importance of the animal welfare is now well known, but little attention is paid to SMEs in terms of optimal environmental conditions for farmers and animals. Although much has been said about sustainability, when choices are involved our society often refers only to comparisons in purely monetary terms; in this sense, an important future development would be to be able to appraise directly the relationship between the increase in building thermal comfort and the subsequent increasing in the quality and quantity of animal productivity (Brugiapaglia and Destefanis, 2012; Casamassima et al., 2001; Szendrő and Dalle Zotte, 2011).

\section{References}

Al-Ragom F. 2003. Retrofitting residential buildings in hot and arid climates. Energy Convers. Manage. 44:2309-19.

Berge E. 1997. Housing of sheep in cold climate. Livestock Prod. Sci. 49:139-49.

Brixius L. 2011. Google SketchUp workshop. Modeling, visualizing, and illustrating. Elsevier, Burlington. Available from: http://www.sciencedirect.com/science/article/pii/B9780240816272000329

Brugiapaglia A., Destefanis G. 2012. Influence of the housing system on meat quality of double muscled Piemontese young bulls. Livestock Sci. 145:73-8.

Caroprese M. 2008. Sheep housing and welfare. Small Ruminant Res. 76:21-5.

Casamassima D., Sevi A., Palazzo M., Ramacciato R., Colella G.E., Bellitti A., 2001. Effects of two different housing systems on behaviour, physiology and milk yiet of Comisana ewes. Small Ruminant Res. 41:151-61.

Charlot-Valdieu C., Outrequin P. 2011. An approach and a tool for setting sustainable energy retrofitting strategies referring to the 2010 EPBD. Inform. Constr. 63:51-60.

Chiappini U., Fichera R.C., Mennella V. 1994. Metaprogettazione per l'edilizia zootecnica. Ed. BE-MA, Milan, Italy [in Italian].

Chioua Y.S., Carleyc K.M., Davidsond C.I., Johnsone M.P., 2011. A high spatial resolution residential energy model based on American Time Use. Survey data and the bootstrap sampling method. Energy Build. 43:3528-38.

Chiumenti R. 1987. Costruzioni rurali. Edagricole, Bologna, Italy.

Dascalaki E., Santamouris M. 2002. On the potential of retrofitting scenarios for offices. Build. Environ. 37:557-67.

Díaz C., Cornadó C., Llorens I., Pardo F., Hormías E. 2012. Un estudio de caso: la rehabilitación de los edificios de viviendas del barrio de La Mina en Sant Adrià del Besòs (Barcelona). Análisis funcional y de las condiciones de seguridad, habitabilidad y mantenimiento. Inform. Constr. 64:19-34 [in Spanish].

Ecim-Djuric 0., Topisirovic G., 2010. Energy efficiency optimization of combined ventilation systems in livestock buildings. Energy Build. 42:1165-71.

Escorcia 0., Garcia R., Trebilcock M., Celis F., Bruscato U. 2012. Mejoramientos de envolvente para la eficiencia energetica de viviendas en el centro-sur de Chile. Inform. Constr. 64:563-574 [in Spanish].

European Commission. 2002. Directive 2002/91/EC of the European Parliament and of the Council of 16 December 2002 on the energy performance of buildings. In: Official Journal L 001, 04/01/2003, pp 0065-0071. Available from: http://eur-lex.europa.eu/legalcontent/EN/TXT/?uri=CELEX:32002L0091

European Commission. 2010. Directive 2010/31/EU of the European
Parliament and of the Council of 19 May 2010 on the energy performance of buildings. In: Official Journal L 153, 18/06/2010, pp 124-146. Available from: http://eur-lex.europa.eu/legalcontent/EN/ALL/?uri=CELEX:32010L0031

European Commission, 2012a. Agriculture, fishery and forestry statistics. Main results - 2010-11.2012 edition. Publications Office of the European Union, Luxembourg. Available from: http://epp.eurostat. ec.europa.eu/cache/ITY_OFFPUB/KS-FK-13-001/EN/KS-FK-13-001EN.PDF

European Commission. 2012b. Directive 2012/27/EU of the European Parliament and of the Council of 25 October 2012 on energy efficiency, amending Directives 2009/125/EC and 2010/30/EU and repealing Directives 2004/8/EC and 2006/32/EC. In: Official Journal L 315, 14/11/2012, pp 1-56. Available from: http://eur-lex.europa.eu/ legal-content/EN/TXT/?uri=CELEX:32012L0027

Fabrizio E., Airoldi G. 2012. Simulazione termoenergetica dinamica di un edificio per l'allevamento suinicolo: strategie edilizie e impiantistiche per l'ottimizzazione del benessere termo igrometrico. AIIA 2012, Conference proceedings, 20-22 September, Firenze, Italy [in Italian].

Goddard P., Waterhouse T., Dwyer C., Stott A. 2006.The perception of the welfare of sheep in extensive systems. Small Ruminant Res. 62:215-25.

Guggenberger J.D., Elmore A.C., Crowb M.L. 2013. Predicting performance of a renewable energy-powered microgrid throughout the United States using typical meteorological year 3 data. Renew. Ener. 55:189-95.

Ihm P., Krarti M., 2012. Design optimization of energy efficient residential buildings in Tunisia. Build. Environ. 58:81-90.

Italian Regulation. 2013. Legge 3 agosto 2013, n. 90. Conversione in legge, con modificazioni, del decreto-legge 4 giugno 2013, n. 63 , recante disposizioni urgenti per il recepimento della Direttiva 2010/31/UE del Parlamento europeo e del Consiglio del 19 maggio 2010, sulla prestazione energetica nell'edilizia per la definizione delle procedure d'infrazione avviate dalla Commissione europea, nonchè altre disposizioni in materia di coesione sociale (13G00133). In: G.U. Ser. Gen. no. 181, 03/08/2013. Available from: http://www.gazzettaufficiale.it/eli/id/2013/08/03/13G00133/sg

Jäkel K. 2003. Analyse der Elektroenergieanwendung und Einsparpotentiale am Beispiel sächsischer Milchviehanlagen. Forschungsbericht Agrartechnik, 414, Martin-Luther-Universität, Halle/Saale, Germany [in German].

Jayasinghe M.T.R., Attalage R.A., Jayawardena A.I. 2003. Roof orientation, roofing materials and roof surface colour: their influence on indoor thermal comfort in warm humid climates. Energy Sustain. Develop. 1:16-27.

Kraatz S., Berg W. 2007. Energy demand for milking dairy cows. ASABE Ann. Intl. Meeting, Minneapolis, MN, USA, paper n. 074175.

Kubba S. 2009. LEED Practices, certification, and accreditation handbook. Ed. Butterworth Heinemann, Oxford, UK.

Kurtulus A., Uygan C. 2010. The effects of Google Sketchup based geometry activities and projects on spatial visualization ability of student mathematics teachers. Procedia Social Behav. Sci. 9:384-9.

Manninen M., Sankari S., Jauhiainen L., Kivinen T., Anttila P., Soveri T. 2008. Effects of outdoor winter housing and feeding level on performance and blood metabolites of suckler cows fed whole-crop barley silage. Livestock Sci. 115:179-94.

Marini D. 2013. Optimization of HVAC systems for distributed generation as a function of different types of heat sources and climatic conditions. Appl. Energy.102:813-26.

Mazo J., Delgado M., Marin J.M., Zalba B., 2012. Modeling a radiant floor system with phase change material (PCM) integrated into a building simulation tool: analysis of a case study of a floor heating 
system coupled to a heat pump. Energy Build. 47:458-66.

Ministry of Economic Development. 2012. Italy's National Energy Strategy: for a more competitive and sustainable energy. October 2012. Ministry of Economic Development, Department of Energy, Rome, Italy. Available from: http://www.sviluppoeconomico.gov.it /images/stories/documenti/20121115-SEN-EN.pdf

Neumann A.L., Millán M.I., Aumente P.A.R. 2005. Investigación e impacto ambiental de los edificios. La energía. Inform. Constr. 57:47-61 [in Spanish].

Nguyen A.T., Reiter S. 2014. A climate analysis tool for passive heating and cooling strategies in hot humid climate based on typical meteorological year data sets. Energy Build. 68:756-63.

Ruà M.J., Lòpez-Mesa B. 2012. Certificaciòn energetica de edificios en Espana y sus implicaciones economicas. Inform. Constr. 64:307-18.

Salama A.A.K., Caja G., Hamzaouia S., Badaouic B., Castro-Costaa A., Facanha D.A.E., Guilherminoe M.M., Bozzi R. 2014. Different levels of response to heat stress in dairy goats. Small Ruminant Res. 121:73-9.

Szendrő Zs., Dalle Zotte A. 2011. Effect of housing conditions on pro- duction and behaviour of growing meat rabbits: a review. Livestock Sci. 137:296-303.

Tedeschi L.O., Nicholson C.F., Rich E. 2011. Using system dynamics modelling approach to develop management tools for animal production with emphasis on small ruminants. Small Ruminant Res. 98:102-10.

Thompson R. 2009. Sustainability of hill sheep flocks in England. Small Ruminant Res. 86:71-3.

Van Laer E., Moons C.P.H., Sonck B., Tuyttens F.A.M., 2014. Importance of outdoor shelter for cattle in temperate climates. Livestock Sci. 159:87-101.

Verbeeck G., Hens H. 2005. Energy savings in retrofitted dwellings: economically viable. Energy Build. 37:747-54.

Yang L., Lam J.C., Liu J., Tsang C.L. 2008. Building energy simulation using multi-years and typical meteorological years in different climates. Energy Convers. Manage. 49:113-24.

Znouda E., Ghrab-Morcos N., Hadj-Alouane A. 2007. Optimization of Mediterranean building design using genetic algorithms. Energy Build. 39:148-53. 